\title{
A giant left adrenal pseudocyst presented as abdominal discomfort and laparoscopic adrenalectomy performed
}

\author{
Yildiz Kemal \\ Bezmialem Vakif University Gastroenterology Clinic, Turkey. \\ Received 13 October, 2013; Accepted 6 May, 2014
}

\begin{abstract}
Adrenal cysts are rare lesions and surgical approach is the best treatment option to treat these lesions. Several studies revealed laparoscopic approach is the most effective and safety to remove benign adrenal cysts. Objective of this case report was to assess the safety and efficacy of laparoscopic approach in the removal of benign giant adrenal cysts. A 21 year old female patient was presented at our gastroenterology out-patient clinic with abdominal pain, fullness filling and constipation. Abdominal ultrasonography showed a cystic lesion in the left adrenal gland with thiny internal septations,11 $\times 9 \mathrm{~cm}$ in diameter. Adrenal functions were normal. Laparoscopic left adrenalectomy was performed.
\end{abstract}

Key words: Adrenal pseudocyst, abdominal mass, adrenalectomy.

\section{INTRODUCTION}

Cysts are a rare pathology of adrenal glands (Sroujreh et al., 1990; Bellanton et al., 1998; Abeshouse et al., 1959; Castillo et al., 2005; Mohan et al., 2003; Schmid et al., 2005). As the development of new diagnostic techniques takes place, the occurrence of adrenal cystic lesions has been rapidly increasing. The majority of them are solid adrenal lesions, but localized fluid collections are also more frequently diagnosed. There are no clear guidelines and recommendations in case of adrenal cysts so far. In this case presentation, we reported a young lady with a giant left adrenal pseudocyst presented as abdominal discomfort in the gastroenterology clinic and laparoscopic adrenalectomy performed as a therapy menagement.

\section{CASE STUDY}

A 21 year old female patient was presented at our gastroenterology out-patient clinic with abdominal pain, fullness filling and constipation. Physical examination showed no abnormality. Biochemistry and whole blood count were normal. Abdominal ultrasound, magnetic resonance imaging and computerized tomography showed that there was a cystic lesion in the left adrenal gland with thiny internal septations, size $11 \times 9 \mathrm{~cm}$ in diameter (Figure 1). Then, echoendoscopy revealed a cyst with $11 \times 8 \mathrm{~cm}$ in diameter. Fine needle aspiration (FNA) was performed with 22 gauge needle. A serous material aspirated and was sent for further investigations such as biochemistry, tumor markers, pathological and microbiologically. All were normal. Then, laparoscopic left adrenalectomy was performed (Figure 2) and showed pseudocyst by pathological examination.

\section{DISCUSSION}

In a previous study (Major et al., 2012), out of the whole 


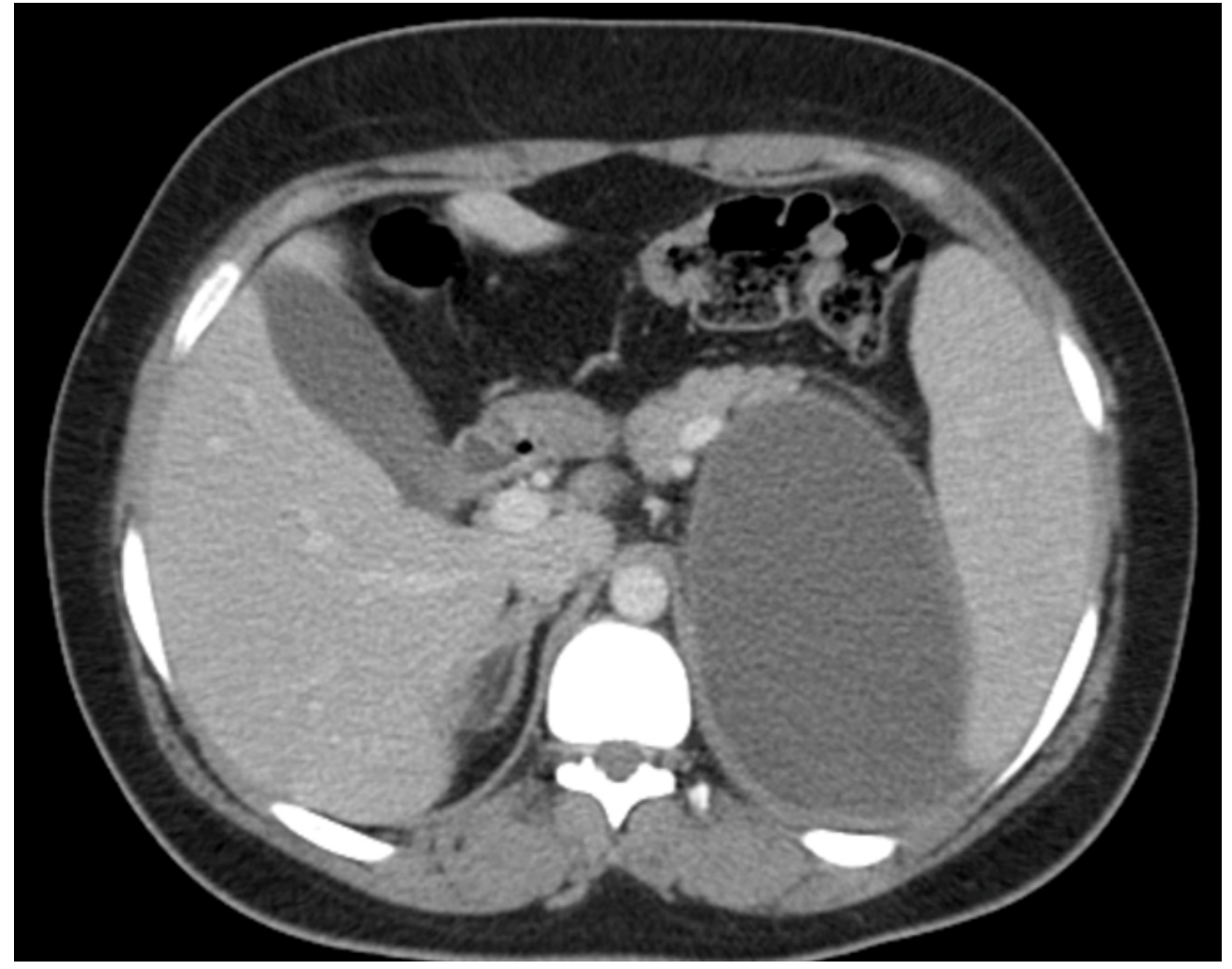

Figure 1. CT image showing an adrenal pseudocyst.

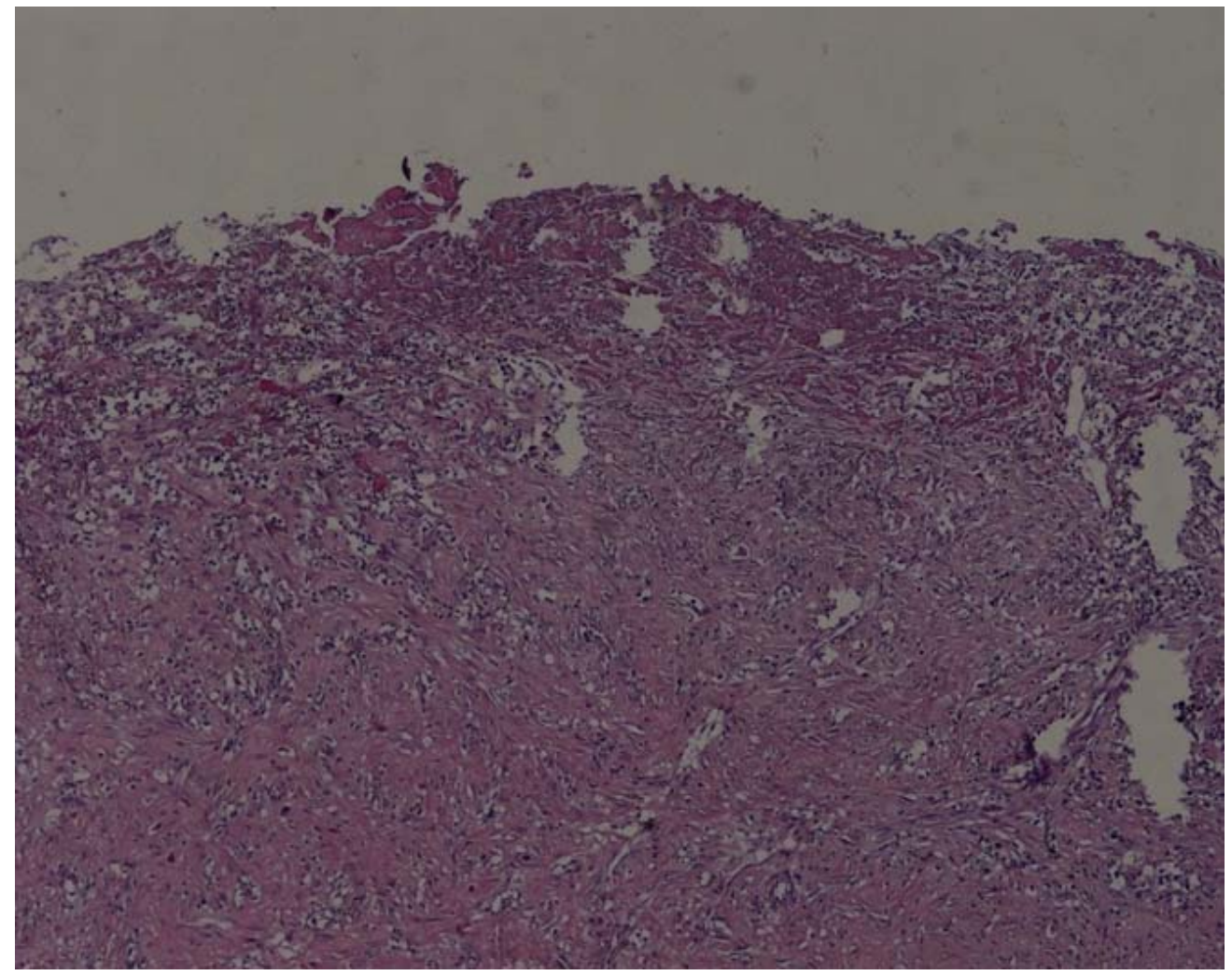

Figure 2. High-powerlight microscopys howing a pseudocyst. Haematoxylinandeosin $\times 400$. 
number of 345 patients who underwent laparoscopic surgery for adrenal tumors, 28 had adrenal cysts. 16 of them $(57 \%)$ were women. The average age of the studied group was 46.4 years ( 25 to 62 years). The average cyst diameter in computed tomography (CT) was $5.32 \mathrm{~cm}(1.1$ to $10 \mathrm{~cm}$ ). Most of the lesions were hormonally inactive (22 patients). Pathological analysis revealed 4 (14\%) pheochromocytomas and $2(7 \%)$ dermoidcysts and in case of $22(79 \%)$ patients, the postoperative material was profiled by pathologists as insignificant according to potential neoplasmatic transformation risk: 7 (25.5\%) pseudocysts.

The files of 245 patients presenting with adrenal masses was reviewed retrospectively (El-Hefnawy et al., 2009). Twenty-six (11\%) patients presented with adrenal cysts; the mean (standard deviation, range) age at the time of presentation for adults was $41.4(15,17$ to 82$)$ years. The mean (sd, range) size of the cysts was $10(3.5$, 5 to 18) $\mathrm{cm}$. Surgical intervention was the treatment of choice in 21 patients. At a mean follow-up of 90 months all patients were symptom free, with no radiological evidence of recurrence. Unlike aspiration of cyst contents, the ocurrence of adrenal cysts after surgical removal is unlikely. Laparoscopic adrenalectomy is a safe and effective treatment for benign adrenal cysts.

In this presentation, we reported a young lady presented abdominal pain, fulness and constipation for gastroenterology, and further analysis showed a giant left adrenal pseudocyst. Laparoscopic adrenalectomy was performed due to the adrenal cystic lesions. In the right side lateral position, transperitoneal three trocar technique was used for surgical operation. After carbondioxide infusion one camera and two dissection trocars were inserted into the peritoneal cavity. Very carrefully, dissection was performed for finding renal and adrenal veins. After renal vein was appeared, adrenal vein was founnd superomedially. Adrenal vein was ligated with endo-vascular clips and cut. For the reason of the mass being very large, aspirated percutaneously and aspiration hole was clipped for prevention of intraperitoneal spillage of the cystic liquid. Block resection was performed successfully with cystic mass and left adrenal tissue totally. No complications were seen in postoperative period and patient was discharged in postoperative day three. Two months later, CT examination was performed and radiologic image is normal at the operated place.

\section{Conflict of interests}

The authors declare that there is no conflict of interests regarding the publication of this article.

\section{REFERENCES}

Abeshouse GA, Goldstein RB, Abeshouse BS (1959). Adrenal cysts review of literature and report of three cases. J. Urol. 81:711-9.

Bellanton R, Ferrante A, Raffaelli M, Boscherini M, Lombardi CP, Crucitti $F$ (1998). Adrenal cystlesions: report of 12 surgically treated cases and review of literature. J. Endocrinol. Invest. 21:109-14.

Castillo OA, Litvak JP, Kerkebe M, Urena RD (2005). Laparoscopic management of symptomatic and large adrenal cysts. J. Urol. 173:915-7.

El-Hefnawy AS, El Garba M, Osman Y, Eraky I, El Mekresh M, Ibrahim el-H (2009). Surgical management of adrenal cysts: single-institution experience. BJU Int. 104(6):847-50.

Major $P$, Pędziwiatr $M$, Matłok $M$, Ostachowski $M$, Winiarski $M$, Rembiasz K,Budzyński A (2012). Cystic adrenal lesions - analysis of indications and results of treatment. Pol. Przegl. Chir. 84(4):184-9. PubMed PMID: 22698655.

Mohan H, Aggarwal R, Tahlan A, Bawa AS, Ahluwalia M (2003). Giant adrenal pseudocyst mimicking a malignant lesion. Can. J. Surg. 46:474.

Schmid H, Mussack T, Wornle M, Pietrzyk MC, Banas B (2005). Clinical management of large adrenal cystic lesions. Int. Urol. Nephrol. 37:767-71.

Sroujreh AS, Farah GR, Haddad MJ, Abu-Khalaf MM (1990). Adrenal cyst: diagnosis and treatment. Br. J. Urol. 65:570-5. 